Pak. j. sci. ind. res. Ser. A: phys. sci. 2020 63A(3) 168-175

\title{
A GIS Based Mapping of Ambient Air Quality of Major Sites of Lahore
}

\author{
Saif-ur-Rehman Kashif*, Fatima Tariq and Fariha Arooj \\ Department of Environmental Sciences, University of Veterinary and Animal Sciences, Lahore, Pakistan
}

(received August 29, 2018; revised April 1, 2019; accepted April 9, 2019)

\begin{abstract}
Ambient air pollution is emerging environmental problem in major cities of Pakistan. Service sector growth is $8 \%$ and there is a rapid development of infrastructure in cities especially in transport sector which causes ambient air pollution issues in mega cities. To estimate the level of pollution in the city of Lahore, ambient air quality mapping procedure was used with the help of Haz Scanner HIM-6000 equipped with different sensors and ArcGIS 10.3 software was used for mapping of these pollutants. This study continued for two months from September to October, 2017 for different pollutants like $\mathrm{PM}_{2.5}$, VOCs, Ozone, $\mathrm{NO} x, \mathrm{CO}_{2}, \mathrm{CO}, \mathrm{SO}_{2}$ and $\mathrm{H}_{2} \mathrm{~S}$. From the study, it was concluded that ambient air in Lahore has lot of pollutants especially $\mathrm{PM}_{2.5}, \mathrm{NO}, \mathrm{NO}_{2}, \mathrm{CO}, \mathrm{SO}_{2}$ where as conc. of VOCs, $\mathrm{H}_{2} \mathrm{~S}$ and Ozone was in limits in relation to NEQs for these pollutants.
\end{abstract}

Keywords: ambient air quality mapping, IDW (inverse distance weighted), VOCs, air pollution

\section{Introduction}

Ambient air pollution is the major issue worldwide and causing severe environmental pollution. The harmful substances emitted from the burning of fossil fuels. Various pollutants emitted from industries and automobiles and pollute the environment. It is necessary to deal with this issue that causing severe conditions (Rohde and Richard, 2015). Pollutants emitted from the automobiles includes carbon monoxide, carbon dioxide, carbon black, oxides of nitrogen, and oxides of sulfur, ozone, VOCs and most important particulate matter. Particulate matter includes fine particles that are also dangerous for human health. $\mathrm{PM}_{10}$ and $\mathrm{PM}_{2.5}$ are the major particulates that are harmful for our health and environment (Cepeda et al., 2017). In US about 600 million people affected due to dangerous pollutants that emitted from the heavy traffic. In Asian countries, the development takes place like urbanization which leads towards the greater pollution and also greater impact on people. (Svendsen et al., 2012). According to the Pakistan Health Survey of 2009 to 2010, Pakistan is on sixth number in the list of South Asian countries which creating ambient air pollution. The use of unclean fuels and inefficient technologies used in these countries are the major cause of ambient air pollution (Schikowski, 2014).

The Lahore is located on map at $31^{\circ} 33^{\prime} 16.582^{\prime \prime} \mathrm{N} 74^{\circ}$ $21^{\prime} 25.769^{\prime \prime}$ E. Lahore is in the area of $332 \mathrm{~km}^{2}$ which

*Author for correspondence;

E-mail: rehman.kashif@uvas.edu.pk spread at $1000 \mathrm{~km}^{2}$ due to massive urbanization. Lahore is the second largest city of Pakistan after Karachi with 9.01 million population and World's $15^{\text {th }}$ most populous city. According to, this city has about, the total number of vehicles registered in the city has increased from 70,342 on June 30, 1980 to over 1,160,000 by April 30, 2018 and is growing by over 100 vehicles daily (Bureau of Statistics, 2018). In addition, more than 1.5 million vehicle also enter city daily from four main entry points viz. Multan road at Thokhar Niaz Baig, Saggian Bridge, Babu Sabu Motorway and Ravi Bridge at Batti Chowk (Niazi chowk) owned by remote/rural owners who daily come to city for their jobs, civil courts, business, shopping, national/international travel, health/hospitals and other activities (https://www.dawn.com/news/ 137591). Lahore features a five-season semi-arid climate (Köppen, 1918), with : foggy winter (15 Nov - $15 \mathrm{Feb})$ with few western disturbances causing rain, pleasant spring (16 Feb - 15 April), summer (15 April - June) with dust, rain storms and heat wave periods, rainy monsoon (July - 16 September), and dry autumn (16 September -14 November). The city's highest maximum temperature was $48.3{ }^{\circ} \mathrm{C}$ recorded on May 30,1944 and $48{ }^{\circ} \mathrm{C}$ recorded on June 9, 2007. The lowest temperature recorded in Lahore was $-1{ }^{\circ} \mathrm{C}$, recorded on 13 January 1967. This city has less wide roads except few ones and due to high traffic especially during peak hours in the morning and at school/office off hours, there is huge rush on roads, due to which speed of vehicles is almost zero and thousand vehicles on roads are releasing exhaust 
on roads. This situation further become verse in summer due to very high temperature and lot of dust due to unstable road sides. Sometimes, it becomes very difficult zero breath on road side due to huge dust, exhaust and heavy smoke on roads. This situation becomes better in winter as during winter, these is very low dust due to low temperature and high humidity but smog is becoming a potential threat which prevails during the month of November to December since 2016 each year. Heavy burden of vehicles on roads due to massive transportation system creates high pollution which is further extended due to these specific climatic conditions in this mega city. The purpose of this study was to monitor ambient air pollution on roads in Lahore during Sep to Oct, 2017.

\section{Materials and Methods}

The study was conducted in the Department of Environmental Sciences, University of Veterinary and Animal Sciences Lahore. Data was collected from walled city of Lahore, Shahdara, Mughalpura, Garhi Shahu, Anarkali, Gulshan Ravi, Samnabad, Ichra, Gulberg-III and Allama Iqbal International Air Port. The pollutants monitored were $\mathrm{PM}_{2.5}$, VOCs, $\mathrm{NO}, \mathrm{NO}_{2}$, $\mathrm{CO}, \mathrm{CO}_{2}, \mathrm{SO}_{2}, \mathrm{H}_{2} \mathrm{~S}$ and ozone. The readings were taken from Haz scanner HIM-6000 after 15 min warm up time at each site. It gives 12 readings of pollutants like $\mathrm{PM}_{2.5}$, VOCs, $\mathrm{NO}, \mathrm{NO}_{2}, \mathrm{CO}, \mathrm{CO}_{2}, \mathrm{SO}_{2}, \mathrm{H}_{2} \mathrm{~S}$ and ozone simultaneously. Ambient air was monitored and mapped at an interval of one week for 8 weeks and data was collected at 8:00 am, 12:00 pm and at 4:00 pm from all these sites. Readings of all these pollutants were taken from the period of September to October for comparison between concentrations of pollutants on all sites. GPS Etrex-20 was used for locating positions of the sites of sampling. ArcGIS 10.3 software from Environmental Systems Research Institute, Inc. (ESRI) was used for mapping purpose. Interpolation technique was used in ArcGIS for the preparation of all maps. For the presentation of final results, SPSS-20 was used. Repeated measure design is the methodology was used to find the association between concentrations of pollutants and time with respect to all areas.

\section{Results and Discussion}

In Fig.1, map shows the dispersion range of $\mathrm{PM}_{2.5}$ in different sites of Lahore during the month of September. The concentration range shows in the form of colour codes. In this map the highest concentration of $\mathrm{PM}_{2.5}$ monitored and mapped in portion with the range of 149.81-153.31. The moderate concentration observed is 135.76-139.26 which include Shahdara and walled city, Lahore. Anarkali lies in between the lowest range which is 121.7-125.21. In Fig. 2, map shows the dispersion range of VOCs in different sites of Lahore during the month of September. In this map the highest concentration of VOCs monitored and mapped in portion with the range of 316.07-343.55. The areas which lie in this portion are airport and Gulberg III. The moderate concentration range is $178.63-206.11$ which is observed in Garhi Shahu. The lowest values observed are 96.15123.64 (Rasheed et al., 2015). In Fig. 3, map shows the

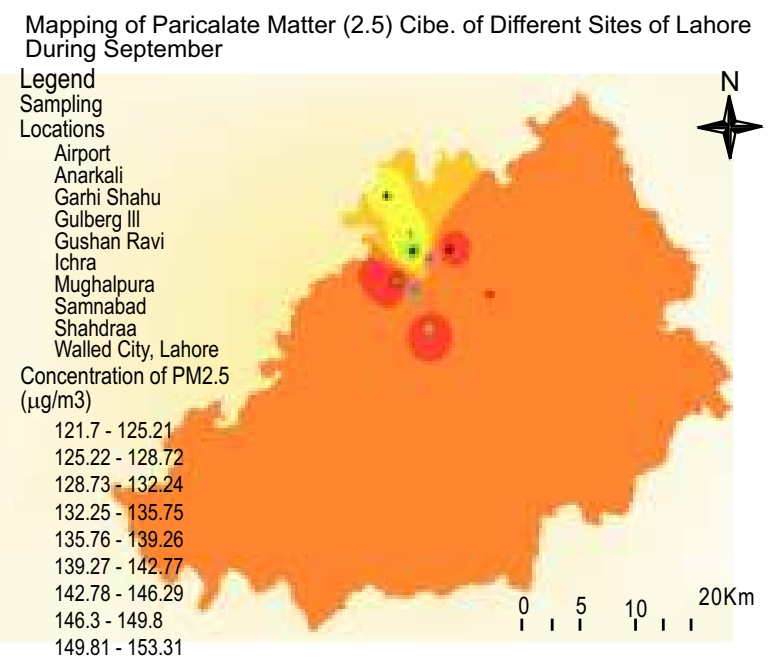

Fig. 1. Map for $\mathrm{PM}_{2.5}$ of September.

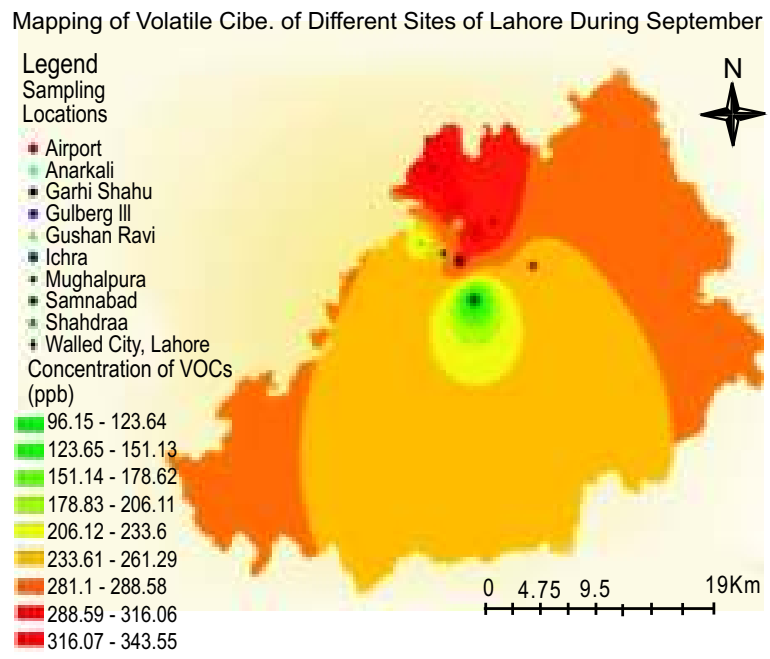

Fig. 2. Map for VOCs of September. 
dispersion range of Nitrogen oxide (NO) in different sites of Lahore during the month of September. In this map the highest concentration of NO monitored and mapped in portion with the range of 576.84-633.17. The area which lies in this portion is Gulberg III. The moderate concentration range is $351.5-407.83$ which is observed in Shahdara. The areas like Gulshan Ravi lies within the lowest range of 126.15-182.49. In Fig. 4, map shows the dispersion range of nitrogen dioxide $\left(\mathrm{NO}_{2}\right)$ during the month of September in different sites of Lahore. In this map the highest concentration of $\mathrm{NO}_{2}$ monitored and mapped in portion with the range of
125.66-131.87. The areas which lie in this portion are Garhi Shahu, Shahdara and walled city, Lahore. Moderate concentration range contains the area of Gulshan Ravi which is 100.77-106.98. Gulberg III lies within the lowest range of 75.88-82.1(Yamamoto et al., 2014). In Fig. 5, map shows the dispersion range CO during the month of September in different sites of Lahore. In this map the highest concentration of $\mathrm{CO}$ monitored and mapped in portion with the range of 6.73-7.43. The lowest values observed are 1.09-1.8 which covers the areas of Airport and Gulberg III. In Fig. 6, map shows the dispersion range $\mathrm{CO}_{2}$ during the

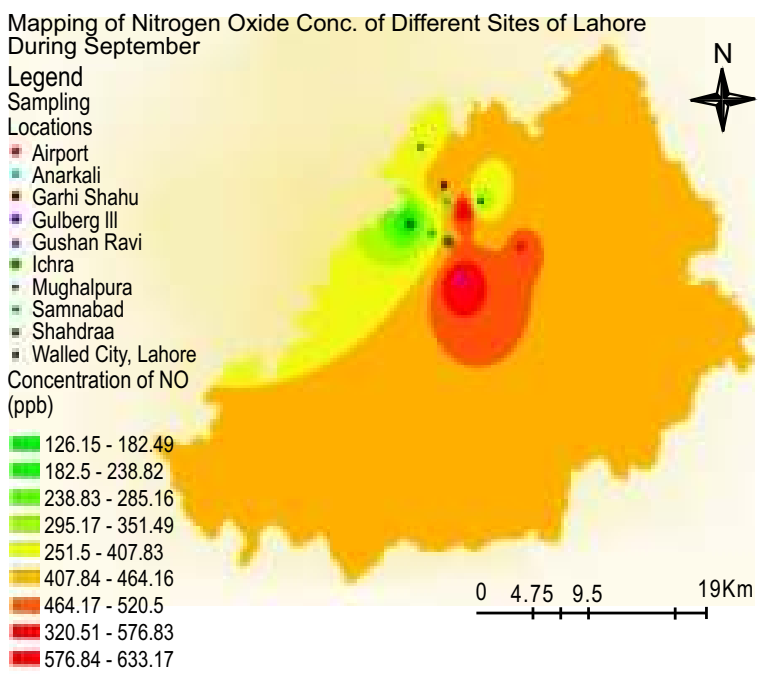

Fig. 3. Map for NO of September.

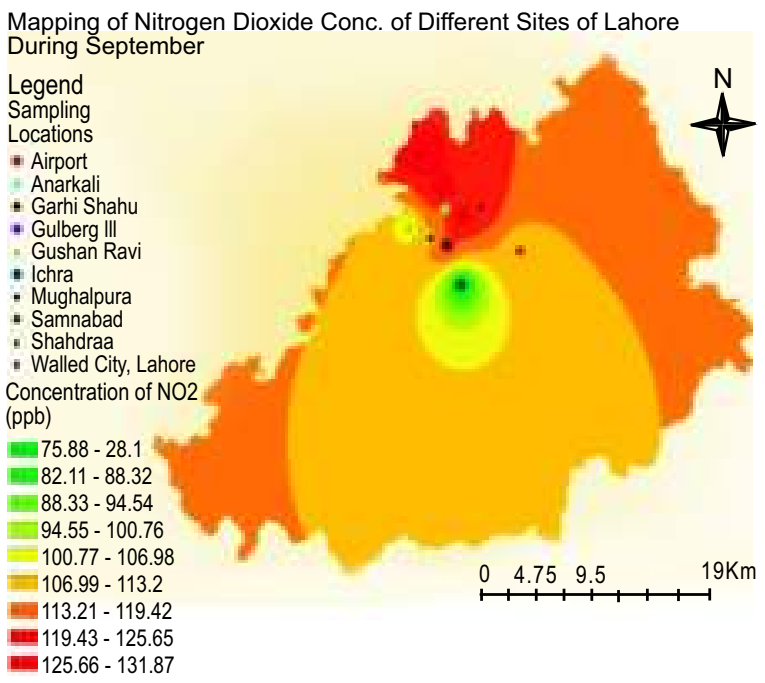

Fig. 4. Map for $\mathrm{NO}_{2}$ of September.

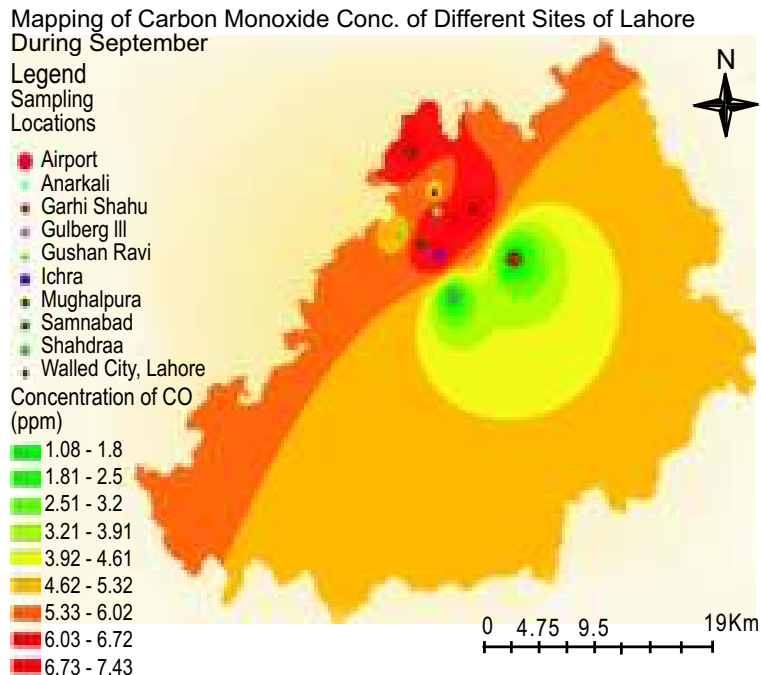

Fig. 5. Map for $\mathrm{CO}$ of September.

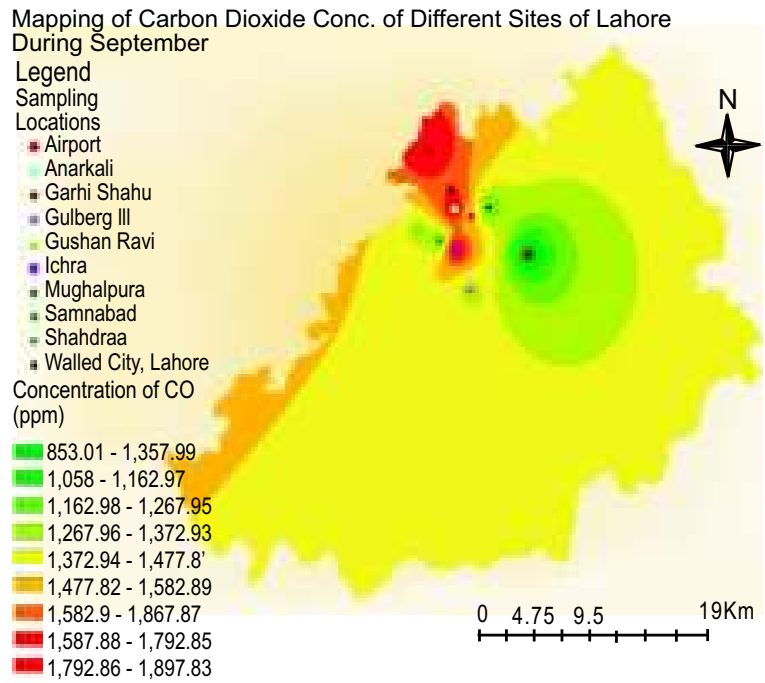

Fig. 6. Map for $\mathrm{CO}_{2}$ of September. 
month of September in different sites of Lahore. In this map the highest concentration of $\mathrm{CO}_{2}$ monitored and mapped in portion with the range of 1792.86-1897.83. The lowest value observed in Airport which is 953.011057.99. In Fig. 7, map shows the dispersion range $\mathrm{SO}_{2}$ during the month of September in different sites of Lahore. In this map the highest concentration of $\mathrm{SO}_{2}$ monitored and mapped in portion with the range of 1405.45-1482.19. The lowest value observed in Airport which is 791.46-868.21. In Fig. 8, map shows the dispersion range $\mathrm{H}_{2} \mathrm{~S}$ in different sites of Lahore during the month of September. In this map the highest concentration of $\mathrm{H}_{2} \mathrm{~S}$ monitored and mapped in portion with the range of 264.1-284.75. The lowest concentration observed in Gulshan Ravi, Samnabad, Ichra and Gulberg III which is 98.78-119.44 (Wellenius et al., 2012). In Fig. 9, map shows the dispersion range $\mathrm{O}_{3}$ during the month of September in different sites of Lahore. In this map the highest concentration among all areas of $\mathrm{O}_{3}$ monitored and mapped in portion with the range of 1.66-1.74. The area which lies in this portion is Walled City, Lahore and Mughalpura. The lowest concentration observed in Gulberg III which is 0.96-1.05. In Fig. 10, map shows the dispersion range of $\mathrm{PM}_{2.5}$ in different sites of Lahore during the month of October. In this map the highest concentration of $\mathrm{PM}_{2.5}$ monitored and mapped in portion with the range of 200.96-204.31. The area which lies in that portion is Gulshan Ravi. The lowest concentration covers the areas of Airport which is 174.04-177.41(Tabinda et al., 2016). In

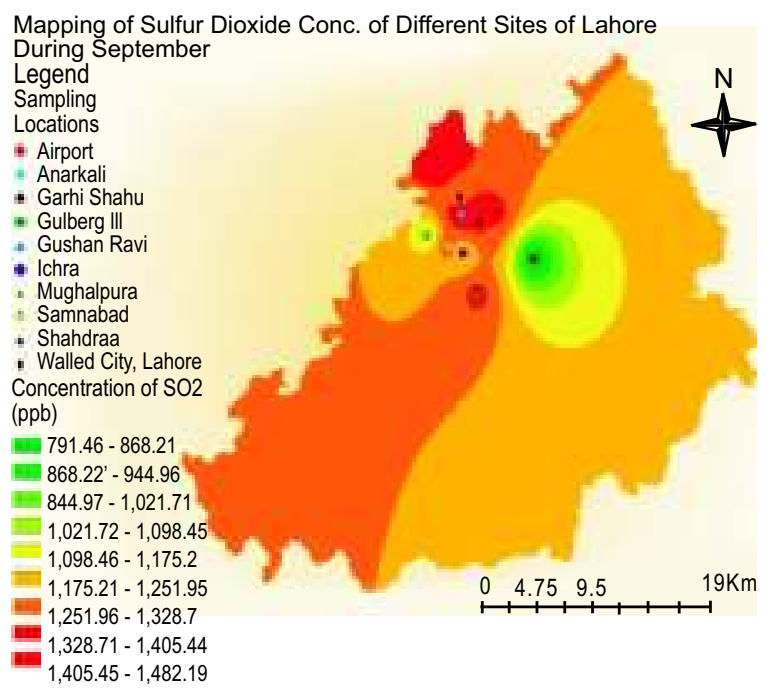

Fig. 11, map shows the dispersion range of VOCs during the month of October in different sites of Lahore. In this map the highest concentration of VOCs monitored and mapped in portion with the range of 457.88-494.75. The lowest values observed are 162.8-199.68 which observe in Shahdara, walled city, Lahore and Gulshan Ravi. In Fig. 12, map shows the dispersion range of Nitrogen oxide (NO) during the month of October in different sites of Lahore. In this map the highest concentration of NO monitored and mapped in portion with the range of 744.22-812.16. The area which lies

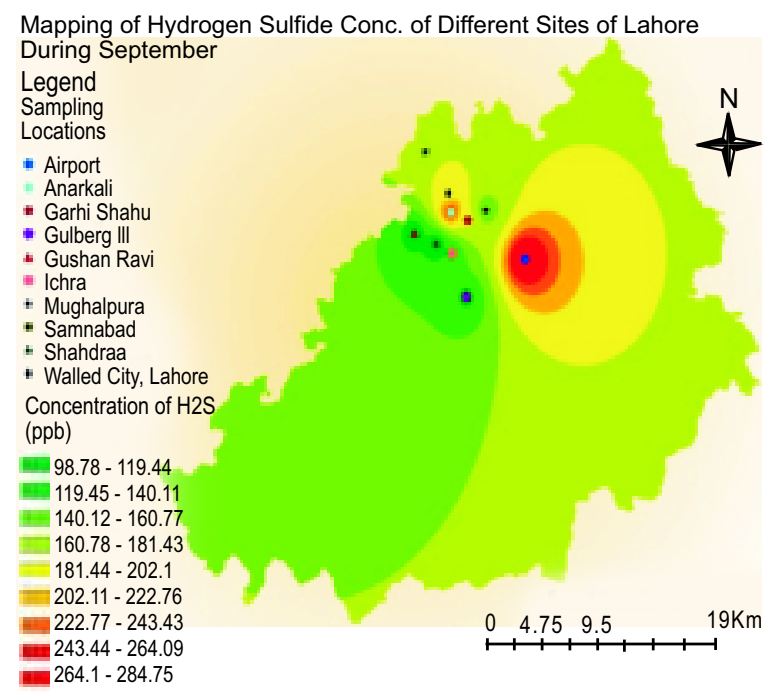

Fig. 8. Map for $\mathrm{H}_{2} \mathrm{~S}$ of September.

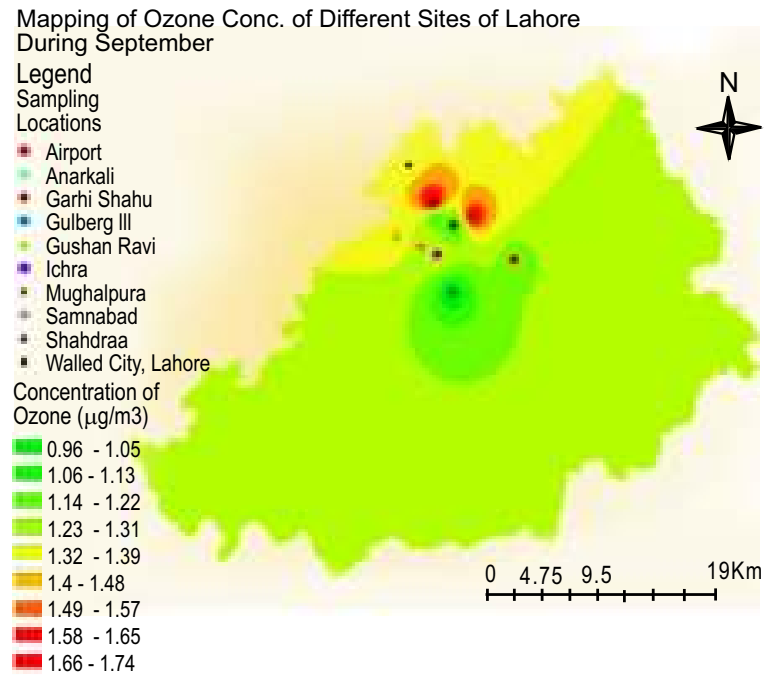

Fig. 9. Map for $\mathrm{O}_{3}$ of September.

Fig. 7. Map for $\mathrm{SO}_{2}$ of September. 
in this portion is Airport. The areas like Gulshan Ravi lies within the lowest range of 200.26-268.57. In Fig. 13, map shows the dispersion range of nitrogen dioxide $\left(\mathrm{NO}_{2}\right)$ during the month of October in different sites of Lahore. In this map the highest concentration of $\mathrm{NO}_{2}$ monitored and mapped in portion with the range of 211.24-224.75. The area which lies in this portion is Shahdara. Airport lies within the lowest range of 103.12116.64. In Fig. 14, map shows the dispersion range CO during the month of October in different sites of Lahore. In this map the highest concentration of $\mathrm{CO}$ monitored and mapped in portion with the range of 7.69-8.47. The

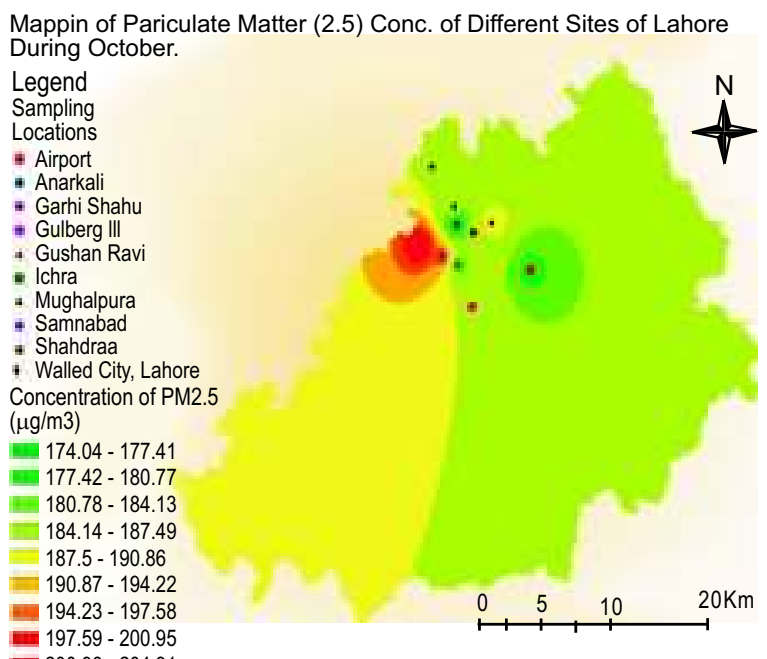

Fig. 10. Map for $\mathrm{PM}_{2.5}$ of October.

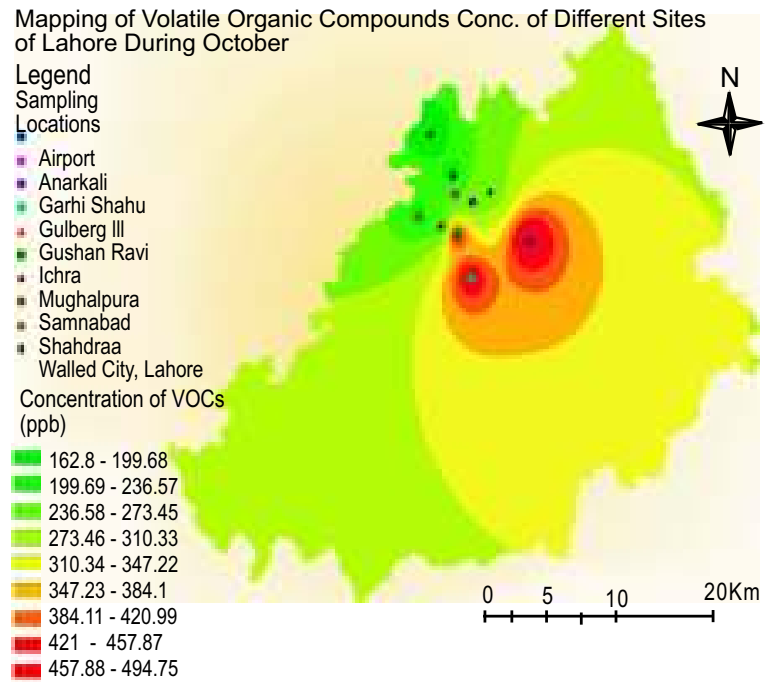

Fig. 11. Map for VOCs of October. areas which lie in this portion are Shahdara, Mughalpura, Garhi Shahu, Samnabad and Ichra. The lowest values observed are 1.41-2.2 which covers the areas of Airport (Tabinda et al., 2016). In Fig. 15, map shows the dispersion range $\mathrm{CO}_{2}$ in different sites of Lahore during the month of October. In this map the highest concentration of $\mathrm{CO}_{2}$ monitored and mapped in portion with the range of 1990.06-2084.84. The area which lies in this portion is Shahdara. The lowest value observed in Airport which is 1231.77-1326.56. In Fig. 16, map shows the dispersion range $\mathrm{SO}_{2}$ during the month of October in different sites of Lahore. In this map the

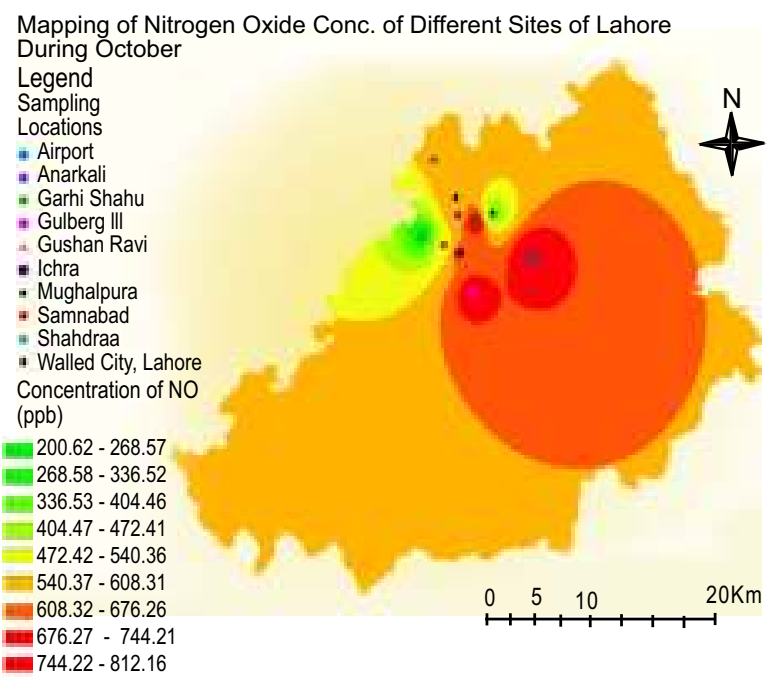

Fig. 12. Map for NO of October.

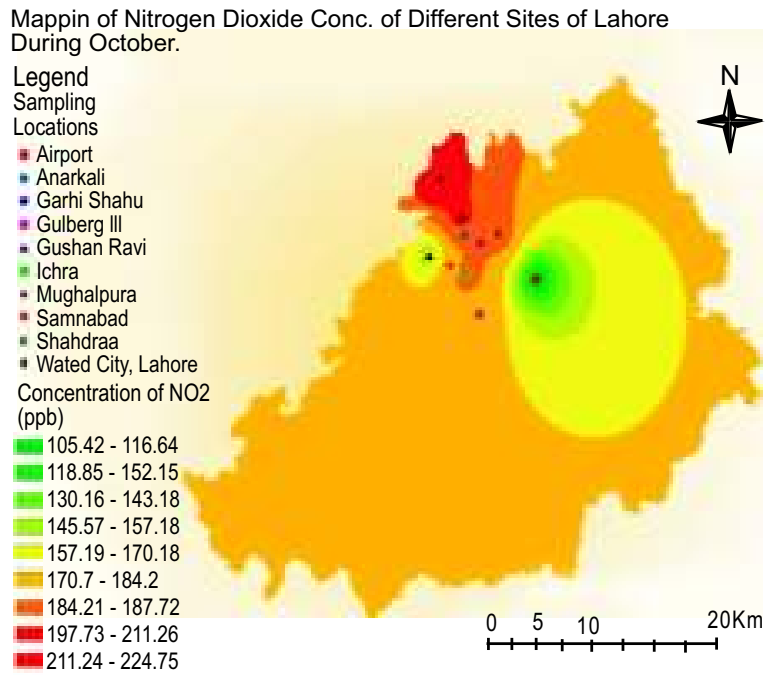

Fig. 13. Map for $\mathrm{NO}_{2}$ of October. 
highest concentration of $\mathrm{SO}_{2}$ monitored and mapped in portion with the range of 1563.19-1637.12. The lowest value observed in Airport which is 971.6-1045.55. In Fig. 17, map shows the dispersion range $\mathrm{H}_{2} \mathrm{~S}$ in different sites of Lahore during the month of October. In this map the highest concentration of $\mathrm{H}_{2} \mathrm{~S}$ monitored and mapped in portion with the range of 338.94-363.54. The area which lies in this portion is Airport. The lowest concentration observed in Gulshan Ravi, Samnabad and Ichra which is 142.09-166.69. In Fig. 18, map shows the dispersion range $\mathrm{O}_{3}$ during the month of

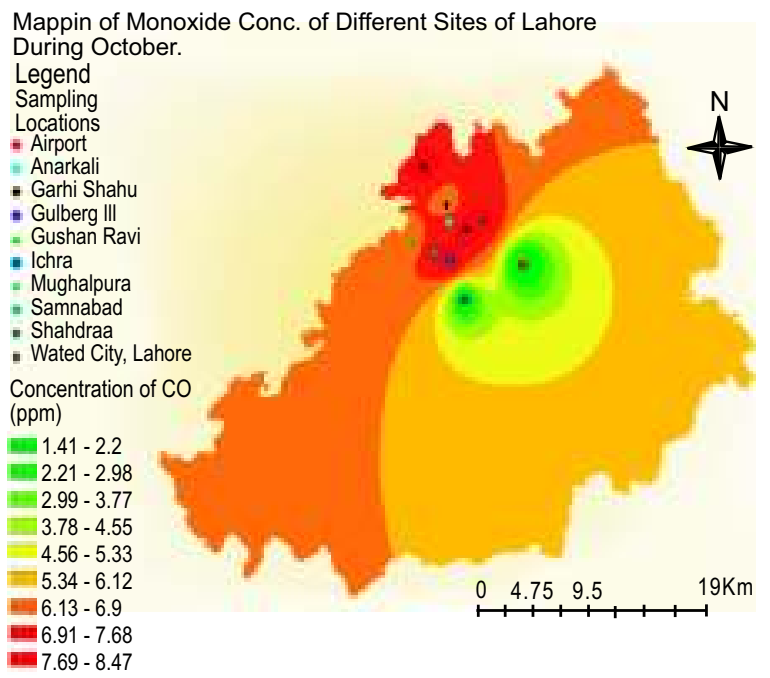

Fig. 14. Map for $\mathrm{CO}$ of October.

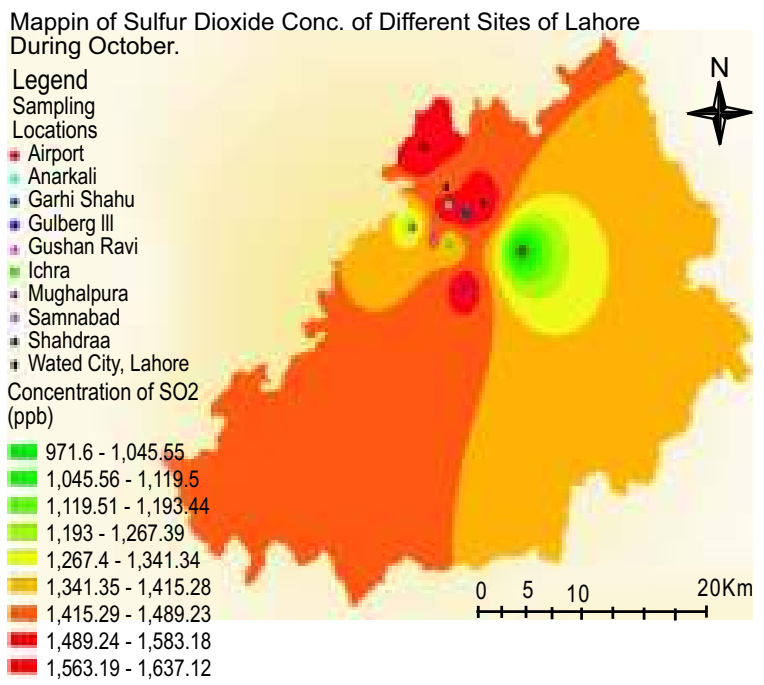

Fig. 15. Map for $\mathrm{CO}_{2}$ of October.
October in different sites of Lahore. In this map the highest concentration among all areas of $\mathrm{O}_{3}$ monitored and mapped in portion with the range of 2.94-3.11. The lowest concentration is observed in Samnabad airport and Ichra present in the range of 1.52-1.7 (Rasheed et al., 2015).

A climatic and seasonal change takes place due to the pollutants emission. So, about $5 \%$ pollution created worldwide due to combustion of fuel in automobiles (Kamal et al., 2016). Emissions from the vehicles reduce the atmospheric visibility and also affect the health of

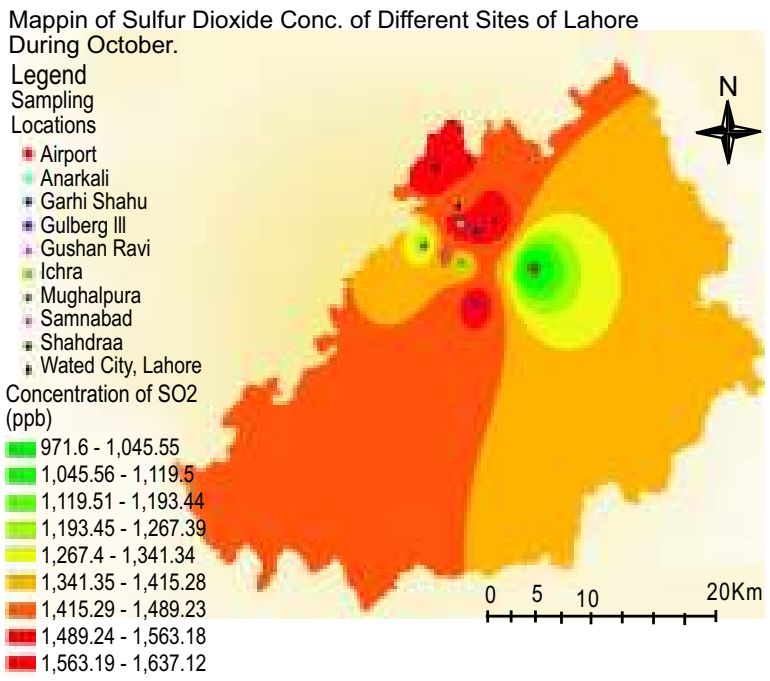

Fig. 16. Map for $\mathrm{SO}_{2}$ of October.

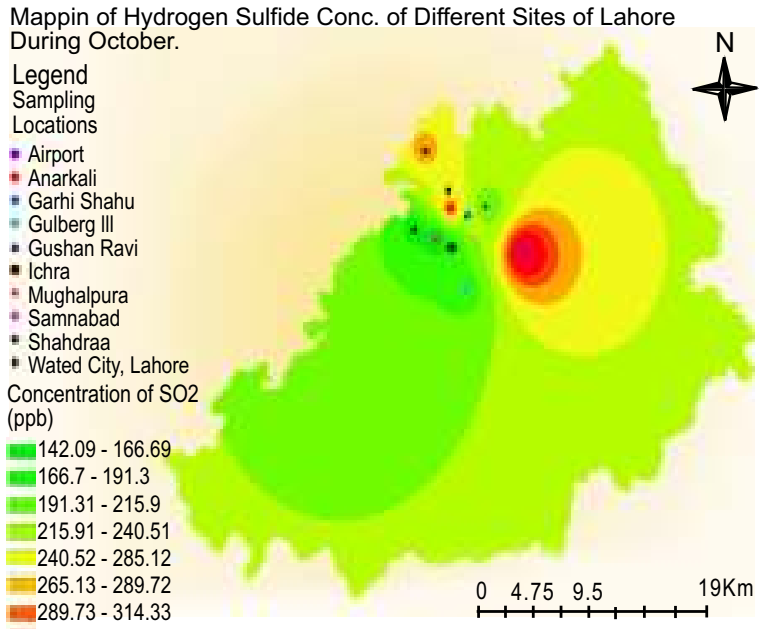

$338.94-363.54$

Fig. 17. Map for $\mathrm{H}_{2} \mathrm{~S}$ of October. 


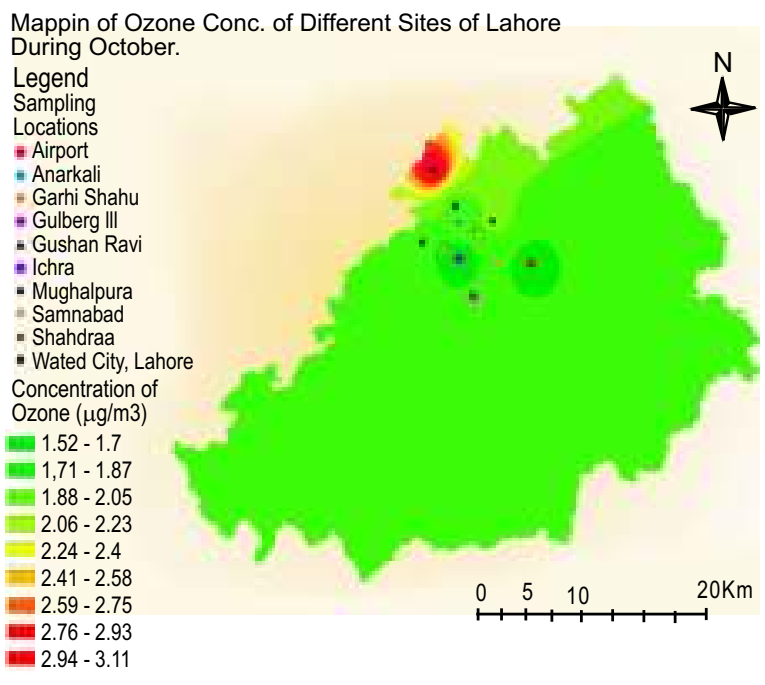

Fig. 18. Map for $\mathrm{O}_{3}$ of October.

human due to the presence of toxic gases like CO. Different countries use the exposure assessment studies to measure the effect of pollutants in the air. Particularly in Vietnam the emission from the road traffic is unavoidable because people in this country use more vehicles in traveling for business purpose (Njee et al., 2016). Rapid urbanization changes the life style of people and their needs, so resulting in the rapid increase in transportation facilities. These changes adopted by about 8.5 million people (Giang and Oanh, 2014). The surveillance of polluted areas on daily basis shows the impacts of ambient air pollution in the form of various diseases like asthma, cardiovascular diseases and other chronic diseases like bronchitis (Vahlsing and Smith, 2012). The ambient air pollution depends upon the dispersion of pollutants in the air. It shows that how densely the areas are populated and how the routes of different passenger allocated and create impact on people and environment (Wellenius et al., 2012). Many particles emitted from the vehicle exhaust which use diesel engines and these particles has size of 20-130 $\mathrm{nm}$ (Hitchcock et al., 2014). The particulate emission from gasoline engine is about $20-60 \mathrm{~nm}$. These are the globally estimated values taken by the keen observation (Brantley et al., 2014). Ambient air pollution measurement depends on wind direction, because pollutants disperse through wind and transported to the nearby areas which are less polluted (Rao et al., 2015). This wind contains the ultrafine particles that include $\mathrm{PM}_{2.5}$ and $\mathrm{PM}_{10}$. These particles inhaled by human and deposited in respiratory system of human and the major cause of lungs diseases. At national level in Pakistan ambient air pollution is the major issue that needs attention (Rasheed et al., 2015). These problems are due to rapid urbanization and the sudden more use of automobiles (Yamamoto et al., 2014). According to the 2017 data of Government of Pakistan the area of Pakistan is $796,095 \mathrm{~km}^{2}$ and the population is about 180.71 million and according to World Bank in 2006 the degradation of environment is about $6 \%$ for GDP of Pakistan. This is due to particulate matter pollution in Pakistan. Many premature deaths among adults and children occur due to these conditions. This problem is due to the use of two stroke engines in the vehicles, burning of fossil fuels and oils like diesel and gasoline (Rasheed et al., 2015). In Lahore and Islamabad the precursor gases which cause pollution are $\mathrm{NO}_{2}$ and $\mathrm{SO}_{2}$ other include particulate matter $\mathrm{PM}_{2.5}$ and VOCs (Volatile Organic Compounds). VOCs emitted by incomplete oxidation during transportation. In Lahore, during winter season about $90 \%$ of carbon black present in the form of $\mathrm{PM}_{2.5}$ which causes major pollution in this area (Tabinda et al., 2016). This study was conducted as a preliminary study for mapping of prevailing ambient air quality, however, to find out contribution of individual sources in ambient air quality, further specific studies are needed.

\section{Conclusion}

From the study, it was concluded that ambient air in Lahore has lot of pollutants especially $\mathrm{PM}_{2.5}, \mathrm{NO}, \mathrm{NO}_{2}$, $\mathrm{CO}, \mathrm{SO}_{2}$ whereas conc. of VOCs, $\mathrm{H}_{2} \mathrm{~S}$ and Ozone was in limits in relation to NEQs for these pollutants. However, further studies during all the seasons of the year with relation to sources may also be carried out in future.

Conflict of Interest. The authors declare no conflict of interest.

\section{References}

Brantley, H.L., Hagler, G.S.W., Kimbrough, E.S., Williams, R.W., Mukerjee, S., Neas, L.M. 2014. Mobile air monitoring data-processing strategies and effects on spatial air pollution trends. Atmospheric Measurement Techniques, 7: 21692014.

Cepeda, M., Schoufour, J., Poli, R.F., Koolhaas, C.M., Dhana, K., Bramer, W.M., Franco, O.H. 2017. Levels of ambient air pollution according to mode 
of transport: a systematic review. Lancet Public Health, 2: 23-34.

Giang, N.T.H., Oanh, N.T.K. 2014. Roadside levels and traffic emission rates of $\mathrm{PM}_{2.5}$ and BTEX in Ho Chi Minh City, Vietnam. Atmospheric Environment, 94: 806-816.

Hitchcock, G., Conlan, B., Kay, D., Brannigan C., Newman, D. 2014. Air Quality and Road Transport: Impacts and Solutions, 87 pp., RAC Foundation, London, UK.

Kamal, A., Syed, J.H., Zhang, L.J., Mahmood G., Malik, R.N. 2016. Profile of atmospheric PAHs in Rawalpindi, Lahore and Gujranwala districts of Punjab province (Pakistan). Aerosol and Air Quality Research, 16: 1010-1021.

Köppen, W. 1918. Klassification der klimate nach temperatur, Niederschlag and Jahreslauf. Petermanns Geographische Mitteilungen, 64: 193-203, 243248. (https://en.wikipedia.org/wiki/Climate_of_ Lahore, accessed on 26-03-2019)

Njee, R.M., Meliefste, K., Malebo, H.M., Hoek, G. 2016. Spatial variability of ambient air pollution concentration in Dar es Salaam. Journal of Environmental Pollution and Human Health, 4: 83-90.

Pakistan Bureau of Statistics. 2018. Population size and growth of major cities./content/population. (Accessed on 26 March, 2019)

Rao, X., Lopez, J.M., Puett, R., Rajagopalan, S., Brook, R.D. 2015. Ambient air pollution: an emerging risk factor for diabetes mellitus. Current Diabetes Reports, 15: 15-33.

Rasheed, A., Aneja, V.P., Aiyyer, A., Rafique, U. 2015. Measurements and analysis of air quality in Islamabad, Pakistan. Earth's Future, 2: 303-314.
Rohde, R.A., Richard, A.M. 2015. Air pollution in China: mapping of concentrations and sources. PloS One, 10: 135-149.

Schikowski, T., Mills, I.C., Anderson, H.R., Cohen, A., Hansell, A., Kauffmann, F., Kramer, U., Marcon, A., Perez, L., Sunyer, J., Kunzli, N., Hensch, N.P. 2014. Ambient air pollution: A cause of COPD. European Respiratory Journal, 43: 250-263.

Svendsen, E.R., Gonzales, M., Mukerjee, S., Smith, L., Ross, M., Walsh, D., Neas, L.M. 2012. GIS-modeled indicators of traffic-related air pollutants and adverse pulmonary health among children in El Paso, Texas. American Journal of Epidemiology, 176: 131-141.

Tabinda, A.B., Munir, S., Yasir, A., Ilyas, A. 2016. Seasonal and temporal variations of criteria air pollutants and the influence of meteorological parameters on the concentration of pollutants in ambient air in Lahore, Pakistan. Pakistan Journal of Scientific and Industrial Research, 59: 34-42.

Vahlsing, C., Smith, K.R. 2012. Global review of national ambient air quality standards for $\mathrm{PM}_{10}$ and $\mathrm{SO}_{2}$. Air Quality, Atmosphere and Health, 5: 393-399.

Wellenius, G.A., Burger, M.R., Coull, B.A., Schwartz, J., Suh, H.H., Koutrakis, P., Schlaug, G., Gold, D.R., Mittleman, M.A. 2012. Ambient air pollution and the risk of acute ischemic stroke. Archive of International Medicines, 172: 229-234.

Yamamoto, S.S., Phalkey R., Malik, A.A. 2014. A systematic review of air pollution as a risk factor for cardiovascular disease in South Asia: Limited evidence from India and Pakistan. International Journal of Hygiene and Environmental Health, 217: $133-144$ 